\title{
ESTUDO DIACRÔNICO DO VOCATIVO NO DIALETO MINEIRO ${ }^{1}$
}

Juliana Costa Moreira (UFMG)

\section{Introdução}

O presente trabalho tem como objeto de investigação o vocativo em construções de língua portuguesa coloquial dos séculos XIX e XX. Buscou-se mais exatamente identificar e descrever o vocativo e, utilizando-se o arcabouço teóricometodológico da Sociolingüística Variacionista, caracterizar as possíveis posições de colocação desse item na sentença ${ }^{2}$. Observou-se que o vocativo apresenta-se em três posições nos contextos em que aparece, a saber: ${ }^{3}$

(1) “Sr. Maurício, nós não fizemos por mal.” [Voc + Oração]

(2) “O que há, Francisco?”

$[\mathrm{Or}+\mathrm{Voc}+\mathrm{Or}]$

(3) "Ouve, Lúcia, os meus conselhos.” [ [Oração + Voc]

Em (1) o termo "Sr. Maurício", denominado vocativo, aparece à esquerda da oração [Voc + Oração], separado dela por vírgula. Em (2), o termo "Francisco" (vocativo), aparece à direita da oração [Oração + Voc], também separado por vírgula. Já em (3), o termo "minha Rosinha" (vocativo) aparece dentro do enunciado [Or + Voc + Or] e, por sua vez, intercalado por vírgulas. O objetivo principal desse trabalho é, então, apresentar uma análise variacionista das sentenças com vocativo, considerando sua posição na oração: [Voc + Oração], [Oração + Voc + Oração] ou [Oração + Voc], utilizando-se um corpus constituído de diálogos de peças de teatro, escritas em Minas Gerais nos séculos XIX e XX. Por esta razão, um dos objetivos principais desta pesquisa é responder às seguintes indagações:

\footnotetext{
${ }^{1}$ Este trabalho se deriva da monografia de bacharelado intitulada "O vocativo na língua caloquial de Minas Gerais nos séculos XIX e XX: uma abordagem variacionista" realizada na Universidade Federal de Ouro Preto, no ano de 2005, sob a orientação da Profa. Dra Mônica G. R. de Alkmim.

${ }^{2}$ Utilizou-se o arcabouço teórico-metodológico da Sociolingüística Variacionista tendo como suporte os textos de Wenreich, Labov e Herzog (1968) e Labov (1972, 1982, 1994).

3 Os exemplos referentes à posição do vocativo dentro da estrutura frasal foram retirados do corpus de Moreira (2005).
} 
(4) Estaria ocorrendo no Português Brasileiro um processo de mudança em progresso envolvendo a posição do vocativo na frase? $\mathrm{Ou}$ melhor, em manifestação do Português pretérito os enunciados apresentavam o vocativo preferencialmente no início, no meio ou no fim das construções. Essa preferência coincide com a tendência do Português comtemporâneo?

(5) Caso seja comprovada a hipótese de mudança em progresso envolvendo a posição do vocativo, seria possível fornecer dados que situem a sua implementação no PB?

Este texto está organizado da seguinte maneira: na primeira seção apresentaremos o quadro geral do tratamento dado ao vocativo no intuito de contextualizar teoricamente o nosso objeto de análise: definição e aspectos mais relevantes; na perspectiva da abordagem tradicional - a começar pelas gramáticas do latim, e ainda, os estudos lingüísticos referentes a esse tema. $\mathrm{Na}$ segunda seção, apresenta-se uma descrição da metodologia adotada para a realização da pesquisa e, na terceira seção, são apresentados os resultados preliminares das análises realizadas. Por fim, expõem-se, as considerações finais.

\section{Definição do vocativo}

$\mathrm{Na}$ comunicação espontânea, normalmente, o vocativo corresponde a um título, nome próprio, sobrenome, termo carinhoso ou até ofensivo, apelido daquela pessoa com quem se quer falar. De acordo com Houaiss (2001: 2877), vocativo é "uma forma lingüística usada para chamamento ou interpelação ao leitor no discurso direto". Em latim, o vocativo é um 'caso' e apresenta, assim, uma marca morfológica. Além disso, é destacado na escrita pelo uso da vírgula e pela possibilidade de vir acompanhado pela interjeição Ó. Muitas das gramáticas do latim se limitam a tratá-lo como um "caso de apelo" ou palavra usada para "chamar". Observou-se que, embora a Nomenclatura Gramatical Brasileira (NGB) situe o vocativo dentro da oração, os gramáticos sentem dificuldade em fazê-lo. O termo é tido por muitos autores como não pertencente à oração, por não apresentar uma relação direta com o verbo. Sendo assim, as Gramáticas Tradicionais e os Dicionários de Lingüística identificam o vocativo em termos de sua 
entonação ou virgulação, mencionando sempre a presença das interjeições $O$, $O h$, Ah que o precedem, como também o isolamento do termo em relação ao restante da oração (Melo, 1978; Luft, 1983; Cunha e Cintra, 1985; Câmara Jr., 1981; Cegalla, 1985; Bechara, 1999). É da mesma opinião, Perini (1995) que trata o vocativo como “termo estranho à estrutura argumental da oração, que constitui por si só uma frase independente". $\mathrm{E}$ afirma, ainda, que uma análise por traços sintáticos não se aplicaria a este termo, uma vez que a sua conexão com a oração não é propriamente sintática. Para o autor, tal ligação não tem a ver com a estrutura da própria oração, mas sim com a organização do discurso. Acompanhando a mesma linha de raciocínio, Bechara (2001) considera-o "uma unidade à parte". ${ }^{5}$ Para ele, o vocativo é "desligado da estrutura argumental da oração e desta vem separado por curva de entoação exclamativa; cumpre uma função apelativa de $2^{\mathrm{a}}$ pessoa, pois, por seu intermédio, chamamos ou pomos em evidência a pessoa a quem nos dirigimos." $\mathrm{O}$ autor acrescenta que algumas vezes vem precedido de $O$, que a tradição gramatical coloca entre as interjeições e que pode ser na realidade considerado um "morfema de vocativo”. Todavia, já dentro dos estudos lingüísticos, Mundim (1981) sugere que há uma estreita correlação do vocativo com a forma de tratamento usada no discurso: a presença do vocativo parece sugerir uma determinada forma de tratamento. A autora sugere que "a opção por determinada expressão vocativa depende diretamente da intenção que temos ao nos dirigir a uma pessoa". ' Segundo esta autora, os vocativos "transmitem nuances diferentes de formalidade" motivo, "têm um elo semântico que os mantêm de certa forma dependentes", das

\footnotetext{
4 PERINI. Gramática descritiva do português, p.91.

${ }^{5}$ BECHARA. Moderna gramática portuguesa, p.460.

${ }^{6}$ BECHARA. Moderna gramática portuguesa, p.460.

7 De acordo com a autora, muitas vezes, tal processo é inconsciente, como ocorre em situações comuns do dia-a-dia (pedido de informação, perguntar as horas, etc.). Entretanto, em situações mais específicas, a escolha do vocativo é decorrente de um processo de opção, consciente e elaborado, depende de um possível interesse pessoal. Esse processo consciente de opção, no corpus analisado pela autora, o qual é constituído por entrevistas com falantes do Rio de Janeiro, foi mais atuante quando o falante utilizava um vocativo não-profissional. $\mathrm{Na}$ utilização de um vocativo profissional, o falante estaria protegido por uma espécie de escudo, uma vez que esse termo não apresenta alto grau de envolvimento do falante. Ele estaria usando uma expressão que iria identificar uma categoria profissional dentro da sociedade.

8 MUNDIM. Formas de tratamento e vocativos no Rio de Janeiro, p.07.

${ }^{9}$ MUNDIM. Formas de tratamento e vocativos no Rio de Janeiro, p.07.
} 
formas de tratamento, uma vez que os tratamentos também apresentam diferentes graus de formalidade. Alkmim e Moreira (2004) em trabalho intitulado O vocativo na Lingua Coloquial do século XIX: uma abordagem variacionista, concluído com o apoio do PIBIC/CNPq, apresentaram uma análise do vocativo considerando, primeiramente, a posição do elemento na oração dentro de um recorte diacrônico: século XIX e $1^{a}$ metade do século XX. O corpus utilizado nesse trabalho é formado por diálogos retirados de peças de teatro escritas em Minas Gerais no século XIX e da $1^{a}$ metade do século XX.

O que se constata a partir da análise dos dados é que em épocas diversas, séculos XIX e XX, o Português do Brasil apresentou preferência ora por uma determinada posição [Oração + Voc], ora por outra [Voc + Oração]. Uma vez que para analisar mudança lingüistica é necessário que se analisem pelo menos três períodos de tempo (Labov 1972), não se pôde afirmar se realmente estava ocorrendo um processo de mudança em progress $0^{10}$ envolvendo as construções com o vocativo, pois consideraram no trabalho o século XIX (como um todo) e a $2^{\mathrm{a}}$ metade do século XX. Por esta razão, no presente estudo, optamos por dividir o século XIX em dois períodos de tempo e levantar os dados da $1^{\mathrm{a}}$ metade do século XX.

\section{Métodos e Procedimentos}

O corpus utilizado no presente trabalho compõe-se de peças de teatro escritas em Minas Gerais nos séculos XIX e XX ${ }^{11}$. A escolha de diálogos de peças de teatro, para a composição de um corpus que se aproxime da língua oral, justifica-se pelo fato de esse tipo de texto se aproximar do uso vernacular, uma vez que tende a ser a representação da fala da personagem que tende a representar a sociedade. Dentre as peças de teatro, deu-se preferência a comédias e teatro de revista, pois esses

\footnotetext{
${ }^{10}$ De acordo com Weinreich, Labov e Herzog (1968) mudança em progresso é uma mudança ainda não completada.

11 Ressalta-se que, na visão da Sociolingüística Variacionista, o estudo de textos de períodos passados da língua, possibilita o detalhamento de mudanças observadas no presente. Isso significa dizer que é possível observar um processo de mudança ainda não completado. A generalização dos fatos observados nesse processo de mudança é possível, pois segundo o processo do Uniformitarismo (Labov, 1972:161 e 1982:20), os mesmos mecanismos que propiciaram uma mudança no passado podem ser os que atuam no presente.
} 
textos caracterizam um estilo mais informal, retratando, assim, com maior fidelidade a fala vernacular.

Para a formação do corpus do Dialeto Mineiro Oitocentista, foram consultadas peças de teatro dos seguintes autores: Martins Pena ( $1^{\mathrm{a}}$ metade do século XIX), Modesto de Paiva e Severiano Nunes Cardoso de Rezende (2a metade do século XIX), sendo que os dois últimos autores nasceram em Minas Gerais. Os dados referentes à $1^{\mathrm{a}}$ metade do século $\mathrm{XX}$ foram retirados de peças de teatro dos autores: Luiz de Oliveira, Américo Werneck, Tancredo Braga, Antônio Rodrigues de Mello, Oscar Argolo do Nascimento, Severiano Nunes Cardoso de Rezende e Durval Lacerda. Já os dados referentes à $2^{a}$ metade do século XX foram retirados de peças de teatro do autor Walmir José. Para evitar que textos que sofreram modificações fossem analisados, foram selecionadas edições com o máximo de rigor possível para a montagem do corpus. Essas peças e esses autores foram escolhidos por atenderem uma característica primordial para o estudo da língua com textos escritos: não possuírem modificações feitas pelo próprio autor ou por terceiros. Buscou-se a $1^{\mathrm{a}}$ edição de cada obra, ou ainda, quando possível, o original manuscrito ${ }^{12}$.

Em Labov (1994) temos que no estudo diacrônico da variação lingüística desenvolve-se a arte de fazer bom uso de maus dados, já que encontrar textos escritos de períodos passados da língua pode significar uma tarefa árdua e muito dificultosa. Uma dificuldade com relação à formação do referido corpus se deu pelo fato de não encontrarmos peças de autor mineiro na $1^{\mathrm{a}}$ metade do século XIX. Desse modo, para que o número de dados não ficasse prejudicado, optou-se por computar peças de um autor brasileiro não nascido em Minas Gerais: Martins Pena. Após a seleção das peças de teatro para a composição do corpus, essas peças foram lidas e as construções contendo vocativo foram transcritas. Os dados foram codificados a partir de hipóteses formuladas no decorrer da pesquisa. Após a codificação, foi realizado o levantamento estatístico dos dados. Foram consideradas

12 A referência bibliográfica de todas as peças e obras utilizadas na composição do corpus encontra-se na bibliografia. 
no presente trabalho, como variável dependente, construções com vocativo. As três variantes consideradas para efeito de levantamento serão: [Voc + Oração], [Or + Voc + Or] e [Oração +Voc]. É importante ressaltar que a posição de um vocativo na elocução é um fator importante em estudo sobre o vocativo, uma vez que pode mostrar um fenômeno de mudança em progresso.

\section{Resultados preliminares}

No corpus analisado, computou-se um total de 2349 estruturas contendo vocativo, das quais 2090 estruturas foram consideradas para a análise de acordo com a sua posição em relação à oração. Um total de 259 construções, contendo vocativos, não foi analisado no presente trabalho. Tais construções foram agrupadas em dois blocos, de acordo com o motivo pelo qual não foram classificados:

(6) 220 dados deste total são estruturas com elipse de verbo e remetem ao fato de o vocativo poder estar separado da oração por mudança de locutor, como mostra Perini (1999:91);

Os outros 39 dados apresentam estruturas (SIM/ NÃO + SENHOR). Observa-se que esses exemplos à semelhança de alguns vocativos, têm em sua composição um pronome (senhor, senhora) e vêm separados por vírgula do restante da oração. Oliveira (1996), em trabalho sobre as construções assertivas no PB (sim senhor), apresenta este tipo de construção com o nome de epíteto e diz tratar-se de afirmações enfáticas. A autora mostra, no tempo real, possíveis mudanças que tenham ocorrido com as respostas assertivas no Português. Para isso, analisa textos de teatro do século XIX e verifica que "a resposta no PB desse século é fortemente subordinada à marca de formalidade”. Quando era necessário o uso do tratamento formal com o pronome de tratamento "senhor" no diálogo, a resposta era formulada com o uso da partícula assertiva, seguida ou não de pronome de tratamento. (Oliveira, 1996 apud Alkmim, 2001). A distribuição das ocorrências com vocativo em relação ao corpus analisado que foram consideradas para a análise pode ser visualizada na Tabela 1, a seguir: 
Tabela 1

Distribuição das estruturas com vocativos do corpus:

\begin{tabular}{||c|c|c||}
\hline Estrutura & № & $\%$ \\
\hline [Voc + Oração] & 714 & 34,1 \\
\hline [Or + Voc + Or] & 175 & 8,4 \\
\hline [Oração + Voc] & 1201 & 57,5 \\
\hline Total & 2090 & 100 \\
\hline
\end{tabular}

Considerando as porcentagens acima apresentadas, verifica-se que a modalidade [Oração + Voc] apresenta-se com mais freqüência em relação às duas outras variantes, que representaram, respectivamente, 34,1\% e 8,4\%. A distribuição das estruturas com vocativo do corpus em relação ao período de tempo em que foram escritas, serão apresentadas aqui, ordenadamente, começando pelo período de tempo mais antigo: T1 ( $1^{\mathrm{a}}$ metade do século XIX), T2 ( ${ }^{\mathrm{a}}$ metade do século XIX), T3 ( $1^{\mathrm{a}}$ metade do século XX) e T4 ( $2^{\mathrm{a}}$ metade do século XX). Estes códigos serão utilizados para efeito de simplificação no momento em que será feita a comparação entre estes quatro períodos de tempo. A distribuição das ocorrências do vocativo, em relação ao período de tempo em que foram escritos, pode ser visualizada na Tabela 2, a seguir:

Tabela 2

Taxa de uso das construções com vocativo de acordo com o tempo:

\begin{tabular}{|c|c|c|c|c|c|c|c|c|c|}
\hline \multirow{2}{*}{ VOCATIVO } & \multicolumn{2}{|l|}{$\overline{T \text { T1 }}$} & \multicolumn{2}{|l|}{ T2 } & \multicolumn{2}{|l|}{ T3 } & \multicolumn{2}{|l|}{ T4 } & \multirow{2}{*}{ TOTAL } \\
\hline & $\mathrm{N}^{\circ}$ & $\%$ & $\mathrm{~N}^{\mathrm{o}}$ & $\%$ & $\mathrm{~N}^{\mathrm{o}}$ & $\%$ & $\mathrm{~N}^{\mathrm{o}}$ & $\%$ & \\
\hline$[\mathrm{Voc}+$ Or $]$ & 270 & 57,0 & 146 & 38,7 & 220 & 38,5 & 78 & 11,7 & 714 \\
\hline [Or+Voc+Or] & 43 & 9,0 & 55 & 14,6 & 19 & 3,3 & 58 & 8,7 & 175 \\
\hline$[\mathrm{Or}+\mathrm{Voc}]$ & 161 & 34,0 & 176 & 46,7 & 332 & 58,2 & 532 & 79,6 & 1201 \\
\hline TOTAL & 474 & 100 & 377 & 100 & 571 & 100 & 668 & 100 & 2090 \\
\hline
\end{tabular}


A comparação dos resultados mostra perfis diferentes, o que sugere estar havendo competição entre as construções com vocativo. A variante [Voc + Oração], que ocorre com mais freqüência em T1 ( $1^{\text {a }}$ metade do século XIX), descende gradativamente ao longo do tempo. A variante [Oração + Voc], no entanto, apresenta perfil ascendente, com maior porcentagem de realização em T4 (2a metade do século XX), perfil esse indicativo de mudança lingüistica. Observa-se, ainda, que a variante $[\mathrm{Or}+\mathrm{Voc}+\mathrm{Or}]$ manteve, ao longo dos períodos de tempo analisados, uma baixa porcentagem de realização e, portanto, continua não sendo a estrutura preferida pelo falante do Português Brasileiro. O gráfico 1 (dados retirados da Tabela 2), a seguir, permite a visualização do perfil da construção que possui perfil ascendente, da construção que possui perfil descendente, assim como a construção que mantém uma baixa porcentagem de realização ao longo dos quatro períodos analisados.

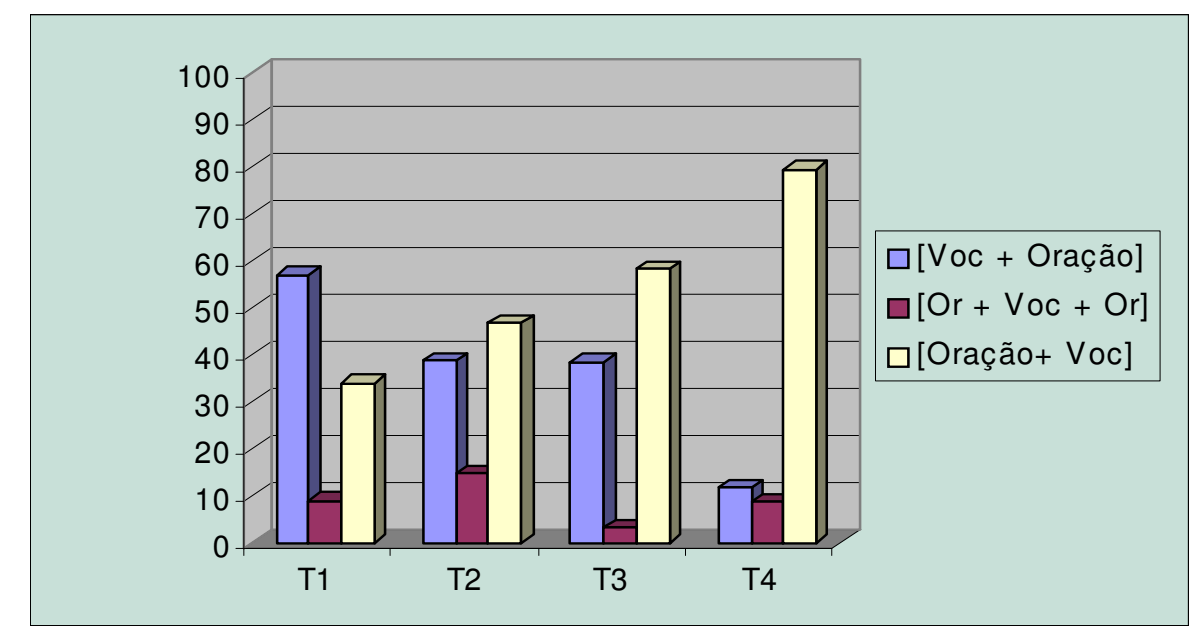

Gráfico 1 - Efeito do fator tempo sobre o uso das construções com vocativo Uma vez realizado o levantamento dos dados do português pretérito, podese tentar responder à questão proposta anteriormente na introdução deste artigo relativa à implementação da mudança. Ou seja, quando passa a ocorrer no PB uma preferência pela estrutura [Oração + Voc]? De acordo com o corpus das peças de teatro analisado (Tabela 1), a preferência por tal estrutura começa a ocorrer na $2^{\mathrm{a}}$ metade do século XIX, quando os resultados da análise apresentam uma porcentagem que passa de 34\% ( $1^{\mathrm{a}}$ metade do século XIX) para 46,7\% na $2^{\mathrm{a}}$ 
metade do século XIX, crescendo para 58,2\% na $1^{\mathrm{a}}$ metade do século XX e chegando a 79,6\% na $2^{\text {a }}$ metade do século XX. É, portanto, na $2^{\text {a }}$ metade do século XIX que começa a ocorrer competição entre as variantes [Oração + Voc] e [Voc + Oração], do que resulta o aumento da porcentagem de realização da primeira e decréscimo da última.

Uma questão intrigante em estudos sobre mudança lingüistica é a investigação da transição, ou melhor, o percurso de uma dada mudança. Para isso é preciso saber como uma língua muda dentro dos sistemas social e lingüístico. A busca de resposta para esta questão não se inclui dentre os objetivos da presente investigação, mas é, sem dúvida, uma motivação para a realização de outros trabalhos.

\section{Considerações finais}

O objetivo geral desse trabalho foi realizar uma análise variacionista de sentenças com vocativo na linguagem coloquial de Minas Gerais dos séculos XIX e $\mathrm{XX}$, considerando as três posições do vocativo, anteriormente, mencionadas. Essa investigação realizou-se com o intuito de:

(a) Apresentar uma descrição das ocorrências de vocativo nas sentenças.

(b) Verificar se está ocorrendo um processo de mudança (ainda não completada), considerando a posição do vocativo, nos quatro tempos do corpus.

A comparação dos resultados mostra perfis diferentes entre as variantes, o que sugere estar havendo competição entre as construções com vocativo. A variante [Oração + Voc], apresenta perfil ascendente, com maior porcentagem de realização na $2^{\mathrm{a}}$ metade do século XX, perfil indicativo de mudança lingüística, enquanto a variante [Voc + Oração], que ocorre com mais freqüência, na $1^{\mathrm{a}}$ metade do século XIX, decresce gradativamente ao longo dos quatro tempos. A variante [Or + Voc + Or], no entanto, manteve baixa porcentagem de realização nos tempos investigados e continua não sendo a estrutura preferida pelo falante do PB. Os 
dados permitiram, ainda, concluir, que a implementaşão dessa mudança lingüística deu-se na $2^{\mathrm{a}}$ metade do século XIX, quando os resultados da análise apresentam uma porcentagem que vai de 34\% (T1) para 79,6\% (T4).

\section{Referências Bibliográficas}

I - Corpus

BRAGA, T. Terra Ideal (Manuscrito Acervo Clube Teatral A. Azevedo) - Biblioteca da UFSJ, 1915.

JOSÉ, Walmir. Um Sobrado em Santa Teręa (Manuscrito), 1999.

JOSÉ, Walmir. Aniversário de casamento (Manuscrito), 1999.

JOSÉ, Walmir. Vô Doidim (Manuscrito), 1999.

JOSÉ, Walmir. Ciúmes Delicados (Manuscrito), 1999.

LACERDA, D. Número 1. (Manuscrito do Clube Teatral Artur Azevedo) Biblioteca da UFSJ, 1918.

MELLO, A.R. de. O Tio Bernardo (Manuscrito do Clube Teatral Artur Azevedo) Biblioteca da UFSJ, 1906.

NASCIMENTO, O. A. de. Glorificação Japonesa. (Manuscrito do Clube Teatral Artur Azevedo) - Biblioteca da UFSJ, 1906.

OLIVEIRA, L. de. Scenarios. Juiz de Fora: Typographia Gutemberg J. Ribeiro, 1917.

PAIVA, M. de. A onça. Manuscrito Acervo do Clube Teatral Artur Azevedo Biblioteca da UFSJ. 1897

PAIVA, M. de. Mudança de Capital. Acervo do Clube Teatral Artur Azevedo Biblioteca da UFSJ, 1893.

PENA, M. Comédias de Martins Pena. Ediouro Ed. Tecnoprint ltda. (Ed. Crítica Darcy Damasceno). 394p.

RESENDE, S.N.C. de. As Gêmeas. (Manuscrito do Clube Teatral Artur Azevedo) Biblioteca da UFSJ, 1906.

RESENDE, S.N.C. de. A virgem Martyr de Santarém. Manuscrito Acervo do Clube Teatral A. Azevedo - Biblioteca da UFSJ. 1870. 
RESENDE, S.N.C. de. Santo Antônio nas águas. (Manuscrito do Clube Teatral Artur Azevedo) - Biblioteca da UFSJ, 1906.

WERNECK, A. Lucrecia. Cidade de Minas Gerais: Imprensa Official de Minas Gerais, 1900. 104p

I I - Referências Bibliográficas

ALKMIM, M.G.R. de. As Negativas Sentenciais no Dialeto Mineiro: uma Abordagem Variacionista. Tese de Doutorado, Faculdade de Letras, UFMG, Belo Horizonte, 2001.

de \& MOREIRA, J.C. O Vocativo na Língua Coloquial de Minas Gerais no século XIX: uma abordagem variacionista. CNPq/ UFOP, 2004.

de \& MOREIRA, J.C. O Vocativo na Língua Coloquial de Minas Gerais no século XIX e XX: uma abordagem variacionista. Monografia de Bacharelado/ UFOP, 2005.

BECHARA, E. Moderna Gramática Portuguesa. Ed. Revista e Ampliada. RJ: Ed. Lucerna, 1999.

- Moderna Gramática da Lingua Portuguesa. 37 ed. rev. e. amp. Rio de Janeiro: Lucerna, 2001.

CAMARA JR, J.M. Dicionário de Lingüistica e Gramática. Petrópolis: Ed. Vozes, 1981.

CEGALLA, D.P. Novíssima Gramática da Língua Portuguesa. SP: Nacional, 1985.

CUNHA, C. \& CINTRA, L. Nova Gramática do português Contemporâneo. Rio de Janeiro: Nova Fronteira, 1985. p.155-158.

HOUAISS, A. Dicionário Honaiss da Lingua Portuguesa. $1^{\text {a }}$ ed. Rio de Janeiro: Objetiva, 2001.

LABOV, W. Sociolinguistics patterns. 3 ed. Philadelphia: University of Pensylvania, 1972.

. Building on Empirical Foundations. In: LEHMANNN, W. \& MALKIEL, Y. (eds). Prespective an Historical Linguistic. Amsterdam: Jonh Benjamins. 1982. p. 79-82.

Principles of Linguistic Change. Vol. 1: Internal Factors. Blackwell: Oxford e Cambridge USA, 1994.

LUFT, C. P. Moderna Gramática Brasileira. Rio de Janeiro: Globo, 1983. 
MELO, G. C. de. Gramática Fundamental da Lingua Portuguesa. Rio de Janeiro: Livro Técnico, 1978.

MUNDIM, S.S. de M. Formas de Tratamento e Vocativo no Rio de Janeiro. Dissertação de Mestrado. UFRJ, 1981.

OLIVEIRA, M de. Respostas Assertivas e suas Variações nas Línguas Românicas: o seu papel na aquisição. Tese de Doutorado. UNICAMP. Campinas, 1996.

PERINI, M. A. Gramática descritiva do Português. SP: Ed. Ática, 1995.

WEINREICH, U., LABOV, W. \& HERZOG, M. Empirical Foundations for a Theory of Language Change. In: LEHMANNN, W. \& MALKIEL, Y. (ed). Directions for Historical Linguistics. Austin: University of Texas Press, 1968 p. 97-189. 